\title{
Carcinogénesis Oral y Epigenética
}

\author{
Oral Carcinogenesis and Epigenetics
}

\author{
Michael Torres González'; Bernardita Fuentes Palma ${ }^{2,3}$ \& Ariel Fernando Castro ${ }^{4,5}$
}

TORRES, G. M.; FUENTES, P. B. \& CASTRO, A. F. Carcinogénesis oral y epigenética. Int. J. Odontostomat., 15(4):850856, 2021.

RESUMEN: A pesar de que los procesos epigenéticos son estudiados ampliamente de forma general, no se habían relacionado, hasta ahora, a las alteraciones genéticas mas tradicionales asociadas en la etiopatogenia del cáncer oral. La visión de carcinogénesis tradicional y la de la epigenética convergen en las mismas vías moleculares involucradas en el desarrollo del cáncer, potenciándose durante el proceso de carcinogénesis oral. A continuación se realizará una revisón de las siguientes vías moleculares VEGF-C /VEGFR; HB-EGF /EGFR; Wnt /B-catenina y las ciclinas, desde un punto de vista genético y epigenético para establecer su conexión durante el proceso de carcinogénesis oral.

PALABRAS CLAVE: neoplasias orales, epigenoma.

\section{INTRODUCCIÓN}

El carcinoma de células escamosas o espinocelular de cabeza y cuello es considerado una de las neoplasias malignas más prevalente de la población actual (Massano et al., 2006). Según el Departamento de Estadística e Información de Salud de Chile (DEIS), las causas de muerte por cáncer entre el año 2000 y 2016 representan aproximadamente el $20 \%$ del total de defunciones nacionales. Por su parte, el carcinoma espinocelular oral causa 350.000 muertes a nivel mundial, diagnosticándose 650.000 nuevos casos anualmente (Parkin et al., 2005)

Según Schaaij-Visser et al. (2010), la tasa de sobrevida para pacientes con este diagnóstico en etapas avanzadas, es de solo un $35 \%$ a los 5 años. Esta tasa aumenta, significativamente, a un $50 \%$ al realizar diagnósticos en estadíos iniciales.

Se han establecido múltiples factores etiológicos que actúan como elementos carcinogénicos en el cáncer oral: tabaco, alcohol, virus, agentes físicos y químicos (Scully, 2011), entre otros. La visión tradicionalista, considerada, actualmente, para explicar el desarrollo de los procesos neoplásicos, se basa en que estos agentes inducen modificaciones a nivel del ADN, el cúal al no ser reparado, producirá células mutantes inicidoras del proceso de transformación maligna (Choi \& Myers 2008).

Por otro lado, en la década de los 50 , Waddington descubrió que ciertas condiciones ambientales tenían la capacidad de modificar el fenotipo, determinando que ciertas entidades presentaban la particularidad de influir en la expresión de los genes, surgiendo el concepto de epigenética, por estar sobre los mismos (Noble, 2015).

Actualmente, tras varios cambios a lo largo del tiempo, el concepto de epigenética se ha interiorizado como todos aquellos procesos moleculares altamente sensibles al medio ambiente, heredables por mitosis y/o meiosis, que afectan a la expresión de los genes sin alterar la secuenciación del ADN.

1 Odontólogo CESFAM Paulina Avendaño Pereda, Talcahuano, Chile.

2 Jefa de departamento cirugía y patología, Facultad de odontología, Universidad Andrés Bello, Concepción, Chile.

${ }^{3}$ Docente de pre y postgrado Facultad de cs. de la salud - Escuela de odontología, Universidad de Talca, Chile.

${ }^{4}$ Docente e Investigador Laboratorio de Transducción de Señales y Cáncer, Departamento de Bioquímica y Biología Molecular-Facultad de Ciencias Biológicas, Universidad de Concepción, Chile.

${ }^{5}$ Director Doctorado en Ciencias Biológicas, Área Biología celular y molecular, Universidad de Concepción, Chile. 
En los últimos años, existe un auge referente al estudio de la epigenética, por lo que se le ha otorgado una importancia significativa en los proceso fisiológicos y patológicos de los seres vivos. No es hasta el año 2017 que el concepto de epigenética comienza a ser incorporado en el proceso de carcinogénesis oral (Hema et al., 2017), llevando a la concepción actual que considera que las alteraciones genéticas y epigenéticas están involucradas, de forma conjunta, en el desarrollo de dicho proceso (Sreekumar, 2019; Li et al., 2020).

Carcinogénesis oral. Clásicamente, los mecanismos moleculares asociados a la carcinogénesis se explican como un trastorno estructural del material genético de una célula normal, la cual, tras una sucesiva exposición a estímulos determinados adopta una nueva condición, que será heredada y se sumará a las propias adquiridas por las células hijas tras el proceso de división. Lo anterior determinará el grado de atipia celular, pilar fundamental para la toma de decisiones terapeúticas (Greaves \& Maley, 2012). A la patogenia neoplásica mencionada, actualmente, se le suman los cambios epigenéticos, que rompen el paradigma clásico, al instaurarse como una alteración en la expresión génica.

Los estímulos agresores llevarán a que el tejido comience con procesos de adaptación celular, como la hiperplasia; evento que puede asociarse a la iniciación del proceso carcinogénico. Posterior a la iniciación, en la etapa de promoción, el tejido tras estar sometido constantemente al estímulo agresor alcanzará un punto de no retorno, estableciéndose la lesión celular, la que se caracteriza por diferentes niveles de displasia (atipias celulares), relacionadas, en base a su proporción y localización a una menor o mayor probalidad de transformación maligna en los tejidos. La condición anterior puede evolucionar a carcinoma in situ y finalmente a carcinoma invasor, este último considerado en la etapa de progresión expansión tumoral. Los distintos estadíos antes mencionados se relacionan con el daño genético y los fenómenos moleculares asociados.

Las alteraciones producidas permiten desarrollar en las células hijas, que constituirán la masa tumoral, una serie de características que le otorgan un comportamiento diferente a las que conforman el resto de los tejidos. Así, por ejemplo, destaca la inestabilidad genómica, asociada a proliferación descontrolada por la no regularización interna ni externa del proceso mitótico, la evasión inmunológica, la adquisición de inmortalidad y la resistencia a la muerte programada. A lo anterior se suma la angiogénesis o proliferación de vasos sanguíneos, la que se acompaña de inflamación, generando un aumento de la tasa metabólica. Es a través de estos vasos que el proceso neoplásico obtiene los nutrientes y elementos necesarios para desarrollar su funciones metabólicas de la mejor forma posible. Además de poder ser utilizados, al igual que los vasos linfáticos, para la invasión local y a distancia a través del proceso metastásico (Hanahan \& Weinberg, 2011).

La proliferación celular desmedida se debe básicamente a la desregulación de tres entidades: un aumento del número de células con capacidad proliferativa, una disminución de la tasa de apoptosis y un cambio en la tasa de proliferación o de diferenciación (Kumar et al., 2021). Se debe considerar que estos tres procesos ocurren en paralelo y no de manera consecutiva.

Mecanismos moleculares en cáncer oral. Los diferentes estadíos morfológicos involucrados en el proceso de carcinogénesis oral están acompañados de fenómenos moleculares específicos, determinantes en los cambios experimentados por los tejidos. (Choi \& Myers), evidenciados en etapas iniciales o avanzadas del proceso. Independiente de lo anterior, cualquiera sea la vía de señalización celular producida, inevitablemente confluirán en el núcleo, induciendo cambios genéticos, cuya consecuencia biológica será el aumento en la proliferación celular y la disminución de la diferenciación.

Además de la alteración en la proliferación, ampliamente estudiada en otros cánceres, la alteración de genes como: p53, Ki67, Rb, Bax y Bcl-2 entre otros (Kanavaros et al., 1999; 2000a y b), también son extrapolables al proceso oral.

La aparición de rasgos del cáncer involucrará una serie de señalizaciones que permiten establecer la neoplasia maligna (Hanahan \& Weinberg, 2000). Estas señales se pueden lograr de diversas maneras: producción de autoligandos (estimulación autocrina), activación de células vecinas (estimulación paracrina) y modificación de receptores (aumento del número de receptores o modificación estructural) lo que permite activar vías intracelulares sin la necesidad de un ligando (Hanahan \& Weinberg, 2011).

Como ejemplo de autoligando, el factor de crecimiento de plaquetas (PDGF) se ha observado au- 
mentado en células cancerosas, al igual que su correspondiente receptor (Heldin, 2012). En las neoplasias malignas de cavidad oral se puede observar actividad autocrina en el factor de crecimiento HB-EGF (del inglés, heparin-binding EGF-like growth factor), el cual se asocia in vitro a la activación de EGFR y la expresión de metaloproteinasa-9 (MMP-9), cuya actividad permitirá la remodelación de la matriz y el proceso de invasión (Ohnishi et al., 2012). Otro ejemplo de estimulación autocrina importante, es el factor de crecimiento endotelial vascular (VEGF-C) y su receptor FLT-4 (VEGFR-3), el que estaría implicado en la promoción del crecimiento tumoral y en la génesis del sistema linfático, esto último favorecería el proceso metastásico (Matsuura et al., 2009) (Fig. 1A).

A nivel oral se puede observar la estimulación paracrina. El receptor de quimoquina 7 (CCR7) se ha estudiado como posible marcador de supervivencia para carcinomas de cabeza y cuello, cuya activación estaría mediada por la expresión y secreción de las quimioquinas 19 y 21 (CCL19, CCL21) por los nódulos linfáticos metastásicos. CCR7 actúa como mediador de invasión en células cancerosas, a través de la activación de la quinasa Akt, la cual normalmente se asocia a la activación de la fosfatadinil inositol 3-kinasa (PI3K) por el receptor de tirosina quinasa del factor de creci-
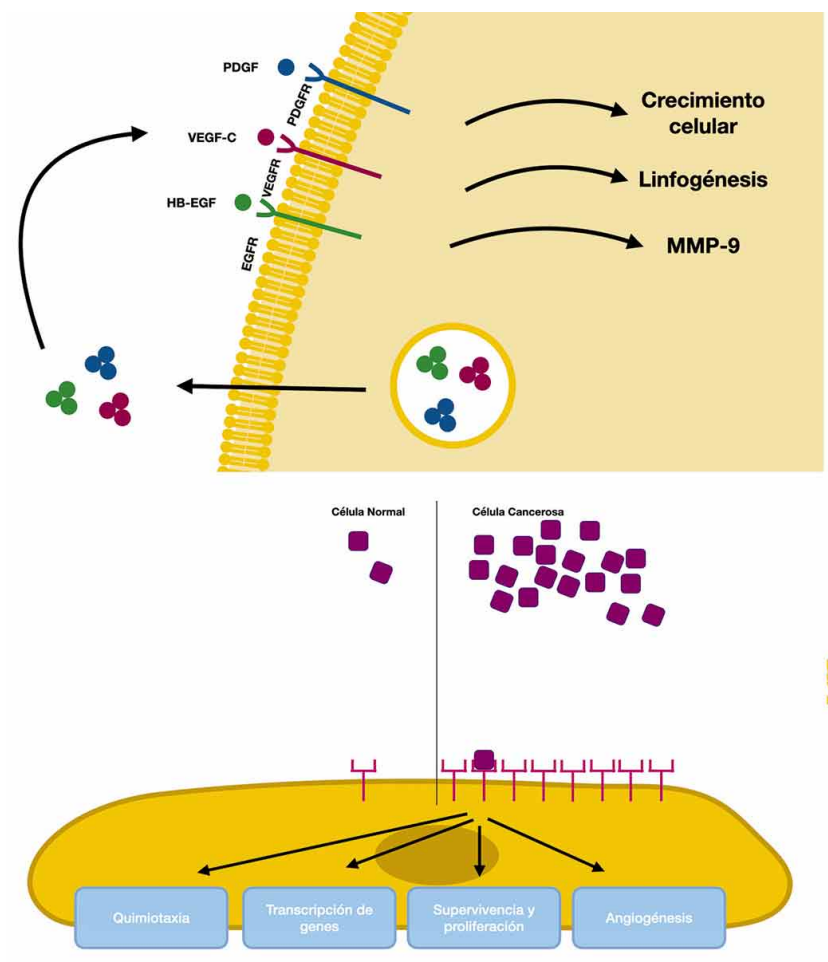

miento epidérmico (EGFR). Sin embargo, CCR7 activaría Akt de una manera independiente de la activación de EGFR, lo que podría explicar la resistencia a quimioterapias y, especialmente, a aquellas terapias dirigidas a inhibir al EGFR (Wang et al., 2008) (Fig. 1B).

Continuando con la estimulación paracrina en cáncer oral, se ha demostrado que el ligando de quimioquina 7 (CCL7) está involucrado en el proceso de progresión tumoral, a través de la interacción entre las células escamosas de carcinoma oral y los fibroblastos asociados a ellas. El co-cultivo de fibroblastos con las células del carcinoma oral aumenta la secreción de CCL7, lo que promueve la migración e invasión de las células cancerosas. En forma similar, se ha demostrado que miofibroblastos asociados a células de cáncer oral liberan el factor de crecimiento activina A, el cual estimula la proliferación de las células cancerosas y el aumento del volumen tumoral (Jung et al., 2010; Sobral et al., 2011).

Los cambios en la expresión de receptores también se asocian a condiciones neoplásicas. La quimioquina CXCL12 (factor derivado de células estromales) y su receptor CXCR4 se encuentran significativamente aumentados en su expresión en tejidos de carcinoma oral de células escamosas con res-

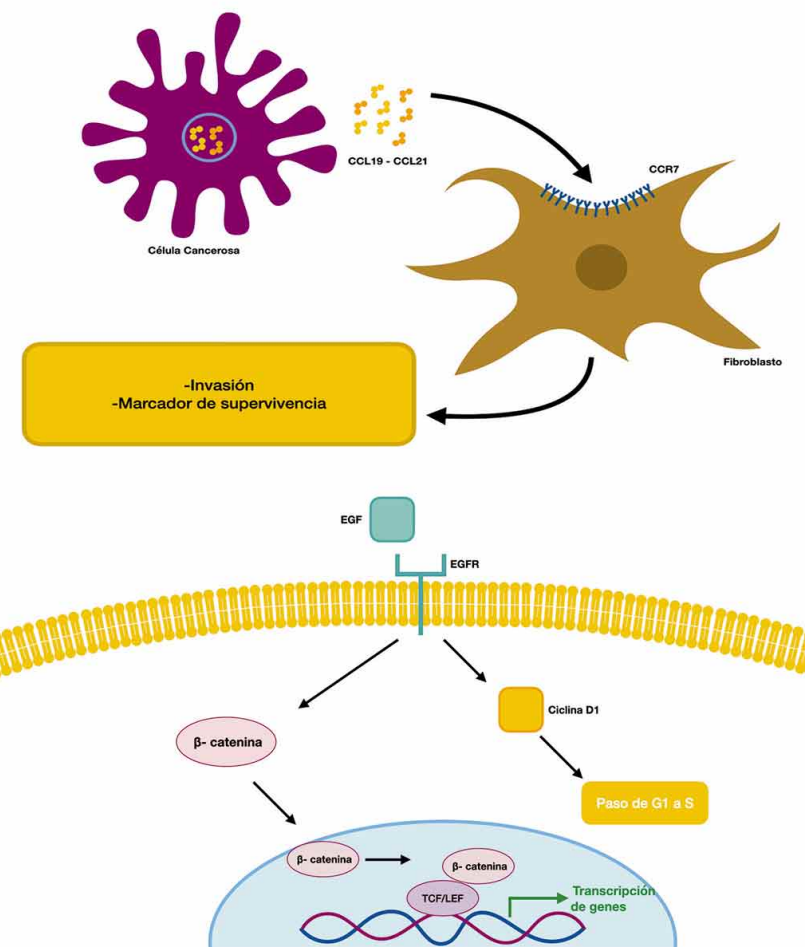

Fig. 1. Se esquematizan algunos mecanismos moleculares del cáncer oral A. Ejemplos de señalización autocrina. B Ejemplo de señalización paracrina. C Ejemplo de modificación de receptores. D Aumento de "segundos mensajeros". 
pecto al epitelio normal. La alteración y activación del eje CXCL12/CXCR4 se ha relacionado con lesiones potencialmente malignizantes y malignas, asociadas a progresión tumoral, angiogénesis, metástasis y sobrevida celular (Teicher \& Fricker, 2010; Xia et al., 2012) (Fig. 1C).

A pesar de la importancia del primer mensajero en la activación del receptor, el segundo es clave para desencadenar la respuesta intracelular. Los segundos mensajeros pueden ser diversos y están estrechamente relacionados con la naturaleza del receptor. Existen diversos segundos mensajeros asociados a distintos receptores, como: PI3K (del inglés, Phosphatidylinositol 3-kinase), MAPK (del inglés, Mitogen-activated protein kinase), IP3 (del inglés, Inositol Triphosphate), AMPc (del inglés, Cyclic adenosine monophosphate) y STAT (del inglés, Signal transducers and activators of transcription) (Kumar et al.). Dentro de las vías de señalización importantes en el cáncer oral se encuentra la vía Wnt / Bcatenina. La activación canónica de esta vía, lleva a la acumulación de B-catenina intracelular y a su localización nuclear, actuando como factor de transcripción que aumenta la expresión de genes asociados a la estimulación de la proliferación celular (Vidya Priyadarsini et al., 2012).

Asociado a la estimulación directa del ciclo celular, se ha demostrado que la Ciclina D1 con sus respectivas quinasas dependientes de Ciclina 4 y 6 (CDK4 y CDK6) estimula el paso de fase $\mathrm{G} 1$ a $S$ en los queranocitos. El aumento de Ciclina D1 induciría un incremento de queratinocitos, sin modificación estructural de los mismos (Woods et al., 2010). La alteración en los niveles de expresión de ciclina D1 en cáncer oral estaría asociada a la activación del EGFR, el cual también favorecería la progresión del cáncer oral a través de una inducción en la acumulación intracelular y localización nuclear de B-catenina (Lee et al., 2010) (Fig. 1D).

Resulta evidente que los fenómenos mencionados influyen de una u otra forma en el desarrollo de las neoplasias malignas. La regulación de los mismos será la clave para la determinación de las características biológicas del tumor, lo que será fundamental en la determinación de su comportamiento clínico.

Epigenética y cáncer oral. La epigénetica se puede describir como el conjunto de procesos moleculares que modifican la expresión de genes, sin alterar la secuencia del ADN, lo que hace que a pesar de tener la misma carga genética se sinteticen proteínas distintas que influyan en el fenotipo del individuo.
Desde hace un par de años, se ha tratado de establecer el rol de la epigenética en la comprensión del desarrollo, estableciéndose su relación con procesos fisiológicos como: la inactivación de uno de los cromosomas $\mathrm{X}$ en los mamíferos femeninos, la activación del pronúcleo masculino en el zigoto o como mecanismo para formar memoria en los linfocitos $\mathrm{T}$ de memoria (Bedregal et al. 2010). De igual manera se ha observado que estos procesos tienen participación en las lesiones patológicas, tales como los trastornos potencialmente malignizantes y lesiones malignas (DíezPérez et al., 2011; Yang et al. 2016). Actualmente, la epigenética ha sido asociada a diversas enfermedades o condiciones tales como la regulación del endotelio vascular, asma, alergia, obesidad y diversas vías moleculares relacionadas con distintos tipos de cáncer (Matouk \& Marsden 2008; Palmer et al., 2014). Sin embargo, la relación entre el cáncer oral y la epigénetica, si bien esta siendo desarrollada por muchos autores, aún, su aplicación clínica esta distante.

Entre los procesos epigenéticos más conocidos podemos mencionar: la metilación del ADN, la modificación de histonas y los ARN de interferencia (iARN) (Taby \& Issa, 2010; Díez-Pérez et al.) que presentan la particularidad de ser altamente sensibles a los procesos medioambientales (Mathews \& Janusek, 2011)

Metilación del ADN. La metilación del ADN es un proceso que consiste en agregar un grupo metilo en el carbono 5 del anillo de Citosina ubicado en el nucleótido de Citosina y generalmente sucede en lugares donde hay una densa población de dimeros Citosina-Guanina (CpG), en algunos textos estos lugares se denominan "islas Citosina-Guanina" (Taby \& Issa). El grupo metilo se transfiere a través de enzimas denominadas metiltransferasas (DNMTs), proceso que sucede en la fase S del ciclo celular (Arand et al., 2012; Bai et al., 2012; Plongthongkum et al., 2014). Normalmente, agregar este grupo metilo se traduce en un silenciamiento de la zona involucrada, debido a la inhibición de factores de transcripción o por reclutamiento de proteínas con dominio de unión CpG (Taby \& Issa).

Para el caso de las ciclinas, se han dilucidado dos mecanismos involucrados. El primero, que afecta de manera directa, consiste en que los promotores de las regiones que codifican para la ciclina $\mathrm{A} 1$ se encuentran considerablemente metilados en tejido tumoral de cáncer oral. Por otro lado, se ha observado una significativa metilación de los promotores de P16, gen que inhibe el paso de fase $\mathrm{G} 1$ o $\mathrm{G} 0$ a fase $\mathrm{S}$. En condiciones normales, P16 se une a CDK4, lo que impide la forma- 
ción del complejo junto a la ciclina D1, deteniendo el ciclo celular; sin embargo, la metilación de este gen, impide que se exprese, de esta manera queda inhabilitada esta forma de regular el ciclo celular (Shaw et al., 2006).

Como se mencionó con anterioridad, el EGFR es altamente expresado en el carcinoma oral y su expresión está relacionada con la supervivencia del paciente, por lo que es un fuerte indicador de pronóstico. De igual manera, se explicó que las quimioquinas tienen participación en el proceso de carcinogénesis oral, en este caso una baja presencia de CXCL14, que es un marcador de pronóstico para metástasis, se correlaciona con la exacerbación de actividad del eje EGF-EGFR. Se cree que este proceso podría deberse a la metilación de promotores de CXCL14 inducido por la activación del eje EGF-EGFR (Nakayama et al., 2017).

Otro ejemplo de metilación que podría servir como marcador de la enfermedad es el que corresponde al gen del receptor de EVGF, FLT-4. Se ha observado que existe una clara hipermetilación del gen correspondiente al receptor de FLT-4 en estadios iniciales y avanzados del cáncer oral, lo que podría utilizarse como un marcador, sin embargo, aún faltan estudios para confirmarlo (Li et al., 2015).

Entre los mecanismos que afectan la vía de señalización canónica de Wnt/B-catenina, se ha observado regulación epigenética de la expresión de proteínas SFRPs (del inglés, secreted Frizzled-related proteins), antagonistas del receptor de Wnt. Se ha descrito que existe hipermetilación en los promotores de las isoformas SFRP-2; SFRP-4 y SFRP-5, lo que significaría un mecanismo que se solapa con el descrito en la visión genética del cáncer, probablemente potenciando el rol de la vía Wnt/B-catenina en la progresión del cáncer oral (Pannone et al., 2010).

ARN de interferencia. Los ARN de interferencia (iARN) son hebras de ARN que interfieren en el proceso de expresión proteica. Los micro ARN (miARN) son los miembros más comunes de la familia de iARN, los cuales están formados por aproximadamente 20 nucleótidos cuya secuencia tiene complementariedad con una región del 3'UTR (sigla del inglés, 3'untraslated región) de los ARN mensajeros (ARNm). La unión de los miARN a la secuencia complementaria del ARNm promueve la degradación del mensajero o la inhibición de su traducción, resultando en una disminución en el proceso de síntesis de la proteína allí codificada (Carthew \& Sontheimer, 2009).
Sin duda alguna, los procesos epigenéticos son reguladores de vías moleculares clásicas y, curiosamente, hoy en día se puede observar que algunos procesos epigenéticos regulan a otros. Por ejemplo, el miARN-486 participa directamente en la regulación del receptor DDR1 (discoidin domain receptor), el cual se encuentra sobrexpresado en distintos tipos de cáncer, incluido el cáncer oral. Este receptor participa en procesos de crecimiento, diferenciación y metabolismo tumoral. La sobre expresión de DDR1 se atribuye a mutaciones somáticas, regulaciones transcripcionales y miARN. Recientemente, se ha descrito que el betel, un agente precursor del cáncer oral se relaciona con la proteína DNMT3, enzima que participa en la metilación del promotor del miARN-486 (Chou et al., 2019). Se ha observado que este miARN se relaciona de manera inversamente proporcional con el receptor DDR1. Es interesante como un hábito, como el betel, afecta un proceso epigenético tal como la metilación, lo que a su vez regula otro proceso epigenético como es el caso de un miARN que participa en la expresión de un receptor involucrado en el proceso de carcinogénesis oral.

Por otro lado, en condiciones fisiológicas normales existen miRNAs que están presentes de manera constitutiva controlando la expresión de genes. Se ha reportado que la pérdida de estos miARN constitutivos, como es el caso del miARN-26a, se podría correlacionar con peor pronóstico en el carcinoma oral de células escamosas (Jia et al., 2014).

Perspectiva. Como es conocido y según los resultados obtenidos por Chou et al., se puede establecer claramente que los procesos epignéticos son susceptibles a factores ambientales; sin embargo, es un área que no está estudiada del todo, y aún menos estudiada en el cáncer oral. Establecer estos ejes nos puede aportar una perspectiva importante para determinar aquellos hábitos que se puedan evitar y establecer nuevos hábitos que ayuden a reducir el proceso carcinogénico (Chou et al.).

Los procesos epigenéticos están relacionados con la carcinogénesis oral y se han establecido procesos moleculares específicos para esto; sin embargo, la información existente no los relaciona a las diferentes etapas del proceso carcinogénico, tales como la invasión o metástasis. Establecer en que momento de la carcinogénesis ocurren determinados procesos nos ayudaría a comprender de mejor manera como funciona el epigenoma en el cáncer oral, pudiéndose desarrollar terapias específicas para la condición presente en cada 
Tabla I. Se puede observar vías moleculares características del proceso de carcinogénesis oral, en el cuál según los distintos autores se han observado alteraciones genéticas y epigenéticas.

\begin{tabular}{lll}
\hline Moléculas o vías afectadas & Alteraciones Genéticas & Alteraciones epigenéticas \\
\hline VEGF-C - VEGFR & Matsuura et al., 2009 & Y.-F. Li et al., 2015 \\
HB-EGF - EGFR & Ohnishi et al., 2012 & Nakayama et al., 2017 \\
Wnt - B-catenina & Vidya Priyadarsini et al., 2012 & Pannone et al., 2010 \\
Ciclina & Woods et al., 2010 & Shaw et al., 2006 \\
\hline
\end{tabular}

paciente. La investigación debería ejecutarse mediante metodologías similares, para poder establecer la conexión entre los procesos genéticos y epigenéticos, orientados a la realización futura de metanálisis de los distintos estudios.

Además de modificar los hábitos, la comprensión de la epigenética en el proceso de carcinogénesis oral nos puede ayudar a desarrollar nuevas terapias para el cáncer. Un ejemplo de esto corresponde al estudio de Zhuang et al. (2017) en donde se ha descrito la participación de miARN en la resistencia a la quimioterapia. Este tipo de estudios podría tener una aplicación directa en terapias para el cáncer, lo que produciría impacto en el futuro cercano.

Sin duda, se prevé que la epigenética jugará un rol fundamental en la medicina de precisión, esto debido a las características de la epigenética, en donde los cambios son muy sensibles al ambiente y son particulares para cada individuo. Por lo anterior, la medicina de precisión, centrada en el estudio individual de los pacientes, en pro de un tratamiento personalizado, deberá inevitablemente abordar la epigenética como una arista en su disciplina (Hamamoto et al., 2019).

\section{CONCLUSIÓN}

La comparativa de diversas vías moleculares del cáncer oral en su visión tradicionalista centrada en cambios genéticos versus la perspectiva de la epigenética, establece claramente, que la acumulación de alteraciones genéticas y epigenéticas llevan al desarrollo del cáncer oral. Estas dos formas de alteraciones no son contradictorias, más bien son sumatorias, explicando de diversos puntos un mismo proceso, ya que, muchas veces confluyen en una vía molecular común (Tabla I). Luego de esta revisión y evidenciando la amplitud del campo de la epigenética y de la gran cantidad de procesos involucrados en la carcinogénesis, es evidente que aún faltan estudios para dilucidar como funciona el epigenoma en el proceso de carcinogénesis oral.
TORRES, G. M.; FUENTES, P. B. \& CASTRO, A. F. Oral carcinogenesis and epigenetics. Int. J. Odontostomat., 15(4):850-856, 2021.

ABSTRACT: Although epigenetic processes are widely studied, no one has related them to the classical genetic processes in oral cancer etiopathogenesis. The traditional carcinogenesis and epigenetic views converge in the same molecular pathways involved in cancer development, enhancing this process. This review will approach the VEGFC/VEGFR, HB-EGF/EGFR, Wnt /B-catenin, and cyclins molecular pathways from the genetic and epigenetic views to establish their connection during the oral cancer process.

KEY WORDS: oral neoplasms, epigenomics.

\section{REFERENCIAS BIBLIOGRÁFICAS}

Arand, J.; Spieler, D.; Karius, T.; Branco, M. R.; Meilinger, D.; Meissner, A.; Jenuwein, T.; Xu, G.; Leonhardt, H.; Wolf, V. \& Walte, J. In vivo control of $\mathrm{CpG}$ and non-CpG DNA methylation by DNA methyltransferases. PLoS Genet., 8(6):e1002750, 2012.

Bai, X.; Zhiguo, S.; Yingzi, F.; Zhaojin, Y.; Lin, Z.; Haishan, Z.; Weifan, Y.; Desheng, H.; Xiaoyi, Mi.; Enhua, W.; Zhihong, Z. \& Minjie, W. Clinicopathological significance and prognostic value of DNA methyltransferase 1, 3a, and 3b expressions in sporadic epithelial ovarian cancer. PloS One, 7(6):e40024, 2012.

Bedregal, P.; Shand, B.; Santos, M. J. \& Ventura-Juncá, P. Aportes de la epigenética en la comprensión del desarrollo del ser humano. Rev. Med. de Chil., 138(3):366-72, 2010.

Carthew, R.W. \& Sontheimer, E. J. Origins and mechanisms of MiRNAs and SiRNAs. Cell, 136(4):642-55, 2009.

Choi, S. \& Myers, J. N. Molecular pathogenesis of oral squamous cell carcinoma: implications for therapy. J. Dent. Res., 87(1):14-32, 2008.

Chou, S. T.; Peng, H. Y.; Mo, K. C.; Hsu, Y. M.; Wu, G. H.; Hsiao, J. R.; Lin, S. F.; Wang, H. D. \& Shiah, S. G. MicroRNA-486-3p functions as a tumor suppressor in oral cancer by targeting DDR1. J. Exp. Clin. Cancer Res., 38(1):281, 2019.

Departamento de Estadísticas e Información de Salud. Defunciones según grupo de edad, región, gran grupo de causas de muerte y sexo. Disponible en: https://deis.minsal.cl/.

Díez-Pérez, R.; Campo-Trapero, J.; Cano-Sánchez, J.; López-Durán, M.; Gonzalez-Moles, M. A.; Bascones-llundain, J. \& BasconesMartinez, A. Methylation in oral cancer and pre-cancerous lesions (Review). Oncol. Rep., 25(5):1203-9, 2011.

Greaves, M. \& Maley, C. C. Clonal Evolution in Cancer. Nature, 481(7381):306-13, 2012.

Hamamoto, R.; Komatsu, M.; Takasawa, K.; Asada, K. \& Kaneko, S. Epigenetics Analysis and Integrated Analysis of Multiomics Data, Including Epigenetic Data, Using Artificial Intelligence in the Era of Precision Medicine. Biomolecules, 10(1):62, 2019. 
Hanahan, D. \& Weinberg, R. A. The Hallmarks of Cancer. Cell, 100(1):57-70, 2000

Hanahan, D., \& Weinberg, R. A. Hallmarks of cancer: the next generation. Cell, 144(5):646-74, 2011.

Heldin, C. H. Autocrine PDGF stimulation in malignancies. Ups. J. Med. Sci., 117(2):83-91, 2012.

Hema, K. N.; Smitha, T.; Sheethal, H. S. \& Mirnalini, S. A. Epigenetics in oral squamous cell carcinoma. J. Oral Maxillofac. Pathol., 21(2):252-59, 2017.

Jia, L. F.; Wei, S. B.; Gan, Y. H.; Guo, Y.; Gong, K.; Mitchelson, K.; Cheng, J. \& Yu, G. Y. Expression, regulation and roles of miR-26a and MEG3 in tongue squamous cell carcinoma. Int. J. Cancer, 135(10):2282-93, 2014

Jung, D. W.; Che, Z. M.; Kim, J.; Kim, K.; Kim, K. Y.; Williams, D. \& $\mathrm{Kim}, \mathrm{J}$. Tumor-stromal crosstalk in invasion of oral squamous cell carcinoma: a pivotal role of CCL7. Int. J. Cancer 127(2):332-44, 2010.

Kanavaros, P.; Stefanaki, K.; Valassiadou, K.; Vlachonikolis, J.; Mavromanolakis, M.; Vlychou, M.; Kakolyris, S.; Gorgoulis, V.; Tzardi, M. \& Georgoulias, V. Expression of p53, p21/waf, bcl-2, bax, Rb and Ki67 proteins in colorectal adenocarcinomas. Med. Oncol., 16(1):23-30, 1999.

Kanavaros, P.; Stefanaki, K.; Vlachonikolis, J.; Eliopoulos, G.; Kakolyris, S.; Rontogianni, D.; Gorgoulis, V. \& Georgoulias, V. Expression of p53, p21/waf1, bcl-2, bax, Rb and Ki67 proteins in Hodgkin's lymphomas. Histol. Histopathol., 15(2):445-53, 2000a.

Kanavaros, P.; Stefanaki, K.; Vlachonikolis, J.; Papalazarou, D.; Rontogianni, D.; Arvanitis, D.; Antonakopoulos, G.; Gorgoulis, V.; Bai, M. \& Agnantis, N. J. Immunohistochemical expression of the p53, p21/Waf-1, Rb, p16 and Ki67 proteins in multiple myeloma. Anticancer Res., 20(6B):4619-25, 2000b.

Kumar, V.; Abbas, A. \& Aster, J. Robbins y Cotran. Patología estructural y funcional + StudentConsult. $10^{\mathrm{a}}$ ed., España, Elsevier, 2021.

Lee, C. H.; Hung, H. W.; Hung, P. H. \& Shieh, Y. S. Epidermal growth factor receptor regulates beta-catenin location, stability, and transcriptional activity in oral cancer. Mol. Cancer, 9:64, 2010.

Li, C. C.; Shen, Z.; Bavarian, R.; Yang, F. \& Bhattacharya, A. Oral cancer: genetics and the role of precision medicine. Surg. Oncol. Clin. N. Am., 29(1):127-44, 2020.

Li, Y. F.; Hsiao, Y. H.; Lai, Y. H.; Chen, Y. C.; Chen, Y. J.; Chou, J. L.; Chan, M. W.; Lin, Y. H.; Tsou, Y. A.; Tsai, M. H. \& Tai, C. K. DNA DNA methylation profiles and biomarkers of oral squamous cell carcinoma. Epigenetics, 10(3):229-36, 2015.

Massano, J.; Regateiro, F. S.; Januário, G. \& Ferreira, A. Oral squamous cell carcinoma: review of prognostic and predictive factors. Oral Surg. Oral Med. Oral Pathol. Oral Radiol. Endod., 102(1):67-76, 2006.

Mathews, H. L. \& Janusek, L. W. Epigenetics and psychoneuroimmunology: mechanisms and models. Brain Behav. Immun., 25(1):25-39, 2011.

Matouk, C. C. \& Marsden, P. A. Epigenetic regulation of vascular endothelial gene expression. Circ. Res., 102(8):873-87, 2008.

Matsuura, M.; Onimaru, M.; Yonemitsu, Y.; Suzuki, H.; Nakano, T.; Ishibashi, H.; Shirasuna, K. \& Sueishi, K. Autocrine loop between vascular endothelial growth factor (VEGF)-C and VEGF receptor3 positively regulates tumor-associated lymph angiogenesis in oral squamoid cancer cells. Am. J. Pathol., 175(4):1709-21, 2009.

Nakayama, R.; Arikawa, K. \& Bhawal, U. K. The epigenetic regulation of $\mathrm{CXCL} 14$ plays a role in the pathobiology of oral cancers. $J$. Cancer, 8(15):3014-27, 2017.

Noble, D. Conrad Waddington and the origin of epigenetics. J. Exp. Biol. 218(6):816-18, 2015

Ohnishi, Y.; Inoue, H.; Furukawa, M.; Kakudo, K. \& Nozaki, M. Heparinbinding epidermal growth factor-like growth factor is a potent regulator of invasion activity in oral squamous cell carcinoma. Oncol. Rep., 27(4):954-58, 2012.
Palmer, D. J.; Huang, R. C.; Craig, J. M.; \& Prescott S. L. Nutritional influences on epigenetic programming: asthma, allergy, and obesity. Immunol. Allergy. Clin. North Am., 34(4):825-37, 2014.

Pannone, G.; Bufo, P.; Santoro, A.; Franco, R.; Aquino, G.; Longo, F.; Botti, G.; Serpico, R.; Cafarelli, B.; Abbruzzese, A.; Caraglia, M.; Papagerakis, S. \& Lo Muzio, L. WNT pathway in oral cancer: epigenetic inactivation of WNT-Inhibitors. Oncol. Rep., 24(4):103541, 2010.

Parkin, D. M.; Bray, F.; Ferlay, J. \& Pisani, P. Global cancer statistics, 2002. CA. Cancer. J. Clin., 55(2):74-108, 2005.

Plongthongkum, N.; Diep, D. H.; \& Zhang, K. Advances in the profiling of DNA modifications: cytosine methylation and beyond. Nat. Rev. Genet., 15(10):647-61, 2014.

Schaaij-Visser, T. B.; Brakenhoff, R. H.; Leemans, C. R.; Heck, A. J. \& Slijper, M. Protein biomarker discovery for head and neck cancer. J. Proteomics, 73(10):1790-803, 2010.

Scully, C. Oral cancer aetiopathogenesis; past, present and future Aspects. Med. Oral. Patol. Oral. Cir. Bucal., 16(3):e306-311, 2011.

Shaw, R. J.; Liloglou, T.; Rogers, S. N.; Brown, JS.; Vaughan, E. D.; Lowe, D.; Field, J. K. \& Risk, J. M. Promoter Methylation of P16, RARb, E-Cadherin, Cyclin A1 and Cytoglobin in Oral Cancer: Quantitative Evaluation Using Pyrosequencing. Br. J. Cancer 94 (4):561-68, 2006.

Sobral, L. M.; Bufalino, A.; Lopes, M. A.; Graner, E.; Salo, T. \& Coletta, R. D. Myofibroblasts in the stroma of oral cancer promote tumorigenesis via secretion of activin A. Oral Oncol., 47(9):84046, 2011.

Sreekumar, V. N. Global scenario of research in oral cancer. J. Maxillofac. Surg., 18(3):354-59, 2019.

Taby, R. \& Issa, J. P. Cancer epigenetics. CA Cancer J. Clin., 60(6):37692, 2010.

Teicher, B. A. \& Fricker, S. P. CXCL12 (SDF-1)/CXCR4 pathway in cancer. Clin. Cancer Res., 16(11):2927-31, 2010.

Vidya Priyadarsini, R.; Senthil Murugan, R. \& Nagini S. Aberrant activation of $\mathrm{Wnt} / \mathrm{b}$-Catenin signaling pathway contributes to the sequential progression of DMBA-Induced HBP carcinomas. Oral Oncol., 48(1):33-9, 2012.

Wang, J.; Seethala, R. R.; Zhang, Q.; Gooding, W.; Van Waes, C.; Hasegawa, H. \& Ferris R. L. Autocrine and paracrine chemokine receptor 7 activation in head and neck cancer: implications for therapy. J. Natl. Cancer Inst., 100(7):502-12, 2008.

Woods, M.; Pant, R. \& Mallya S. M. Cyclin D1 and cyclin D-dependent kinases enhance oral keratinocyte proliferation but do not block keratinocyte differentiation. Int. J. Oncol., 37(6):1471-5, 2010.

Xia, J.; Chen, N.; Hong, Y.; Chen, X.; Tao, X.; Cheng, B. \& Huang, Y. Expressions of CXCL12/CXCR4 in oral premalignant and malignant lesions. Mediators of Inflamm., 2012:516395, 2012.

Yang, C. M.; Wang, T. H.; Chen, H. C.; Li, S. C.; Lee, M. C.; Liou, H. H.; Liu, P. F.; Tseng, Y. K.; Shiue, Y. L.; Ger, L. P. \& Tsai, K. W. Aberrant DNA hypermethylation-silenced SOX21-AS1 gene expression and its clinical importance in oral cancer. Clin. Epigenetics, 8(1):129, 2016.

Zhuang, Z.; Hu, F.; Hu, J.; Wang, C.; Hou, J.; Yu, Z.; Wang, T. T.; Liu, $X$. \& Huang, $H$. MicroRNA-218 promotes cisplatin resistance in oral cancer via the PPP2R5A/Wnt signaling pathway. Oncol. Rep., 38(4):2051-61, 2017.

Dirección para correspondencia:

Michael Torres González

Odontólogo CESFAM

Paulina Avendaño Pereda

Talcahuano - CHILE

E-mail: michael.torresg@gmail.com 